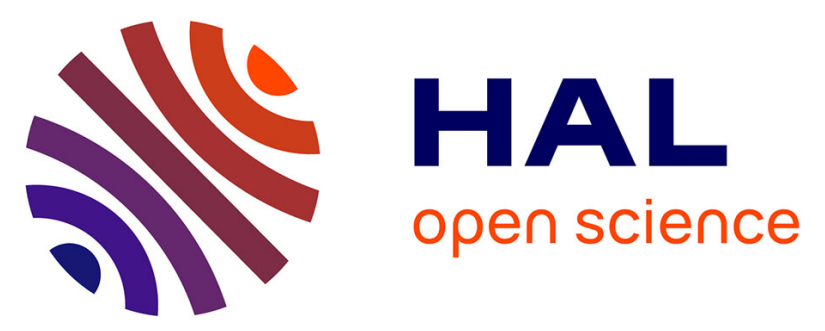

\title{
Selective Laser Decomposition of Silver Oxalate: A New Way of Preparing and Shaping Metallic Silver Patterns
} Isabelle Pasquet, Hoa Le Trong, Valérie Baco-Carles, Véronique Conédéra, Henri Camon, Philippe Tailhades

\section{- To cite this version:}

Isabelle Pasquet, Hoa Le Trong, Valérie Baco-Carles, Véronique Conédéra, Henri Camon, et al.. Selective Laser Decomposition of Silver Oxalate: A New Way of Preparing and Shaping Metallic Silver Patterns. Lasers in Manufacturing and Materials Processing, 2020, 7 (4), pp.513-531. 10.1007/s40516020-00131-1 . hal-03065305

\section{HAL Id: hal-03065305 https://hal.science/hal-03065305}

Submitted on 14 Dec 2020

HAL is a multi-disciplinary open access archive for the deposit and dissemination of scientific research documents, whether they are published or not. The documents may come from teaching and research institutions in France or abroad, or from public or private research centers.
L'archive ouverte pluridisciplinaire HAL, est destinée au dépôt et à la diffusion de documents scientifiques de niveau recherche, publiés ou non, émanant des établissements d'enseignement et de recherche français ou étrangers, des laboratoires publics ou privés. 


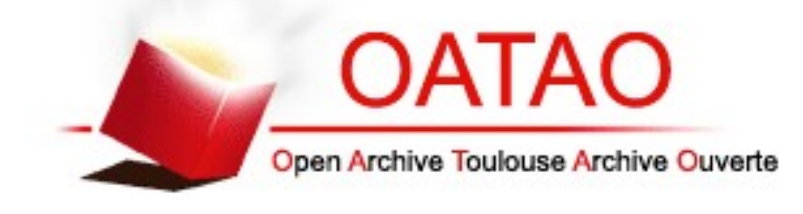

Open Archive Toulouse Archive Ouverte

OATAO is an open access repository that collects the work of Toulouse researchers and makes it freely available over the web where possible

This is an author's version published in: https://oatao.univ-toulouse.fr/27076

Official URL :

https://doi.org/10.1007/s40516-020-00131-1

\section{To cite this version:}

Pasquet, Isabelle and Trong, Hoa Le and Baco-Carles, Valérie and Conédéra, Véronique and Camon, Henri and Tailhades, Philippe Selective Laser Decomposition of Silver Oxalate: A New Way of Preparing and Shaping Metallic Silver Patterns. (2020) Lasers in Manufacturing and Materials Processing, 7 (4). 513-531. ISSN 2196-7229

Any correspondence concerning this service should be sent to the repository administrator: tech-oatao@listes-diff.inp-toulouse.fr 


\title{
Selective Laser Decomposition of Silver Oxalate: A New Way of Preparing and Shaping Metallic Silver Patterns
}

\author{
Isabelle Pasquet ${ }^{1}$ - Hoa Le Trong ${ }^{1}$ - Valérie Baco ${ }^{1}$ - Véronique Conédéra ${ }^{2}$. \\ Henri Camon ${ }^{2} \cdot$ Philippe Tailhades ${ }^{1}$
}

\begin{abstract}
A new process using the selective decomposition of silver oxalate is presented and applied to the production of transparent electrodes on a polymer substrate. It is indeed shown that the silver oxalate $\mathrm{Ag}_{2} \mathrm{C}_{2} \mathrm{O}_{4}$ can be reduced to the metallic silver state by the focused laser beam of a photolithography machine $(\lambda=$ $405 \mathrm{~nm}$, spot size $5 \mu \mathrm{m}$, power between 3 and $100 \mathrm{~mW}$ ). Thin lines of silver of width close to $15 \mu \mathrm{m}$, for optimized insolation conditions, can thus be directly and easily, formed in a layer of oxalate deposited by spin coating on polycarbonate substrate. Since the metal and the oxalate are of very different chemical natures, the residual oxalate is dissolved by an ammoniacal solution without affecting the metal. The silver conductive lines have a very porous vermicular type microstructure which, however, ensures electrical conductivity. The resistive effects, which result from this not very compact filament organi-zation, can be reduced by simply applying a uniaxial mechanical pressure perpendicular to the plane of the substrate. This operation irreversibly reduces the porosity by crushing the silver strands. One by one-centimeters samples with an electrical resistance of $10 \Omega$ and an optical transparency of $95 \%$ (after correcting the effects of the substrate) were thus prepared. Their factor of merit

expressed by $\left(\text { Transparency }{ }_{550 \mathrm{~nm}}\right)^{10} / \mathrm{R}_{\text {pattern }}$, close to $0.059 \Omega^{-1}$, is at the state of the art. The selective decomposition of silver oxalates by a laser beam is therefore a very interesting way to easily make transparent conductors made of thin metallic patterns.
\end{abstract}

Keywords Laser processing · Oxalate $\cdot$ Thermal decomposition · Silver patterns · Transparent electrode

Philippe Tailhades

tailhades@chimie.ups-tlse.fr

Extended author information available on the last page of the article 


\section{Introduction}

Much work has already been conducted on transition metal oxalates to directly use them as anode materials for energy storage [1-3], electrocatalyst for oxygen evolution [4] or burning rate modifier for composite propellants [5, 6]. But they were also be used as chemical precursors to prepare, by thermal decomposition in air or controlled atmosphere, many metallic [7, 8] or mixed oxides powders [9]. The oxalates have generated and generate still attention, because they can be easily prepared by chemical precipitation with different particles size and shape, by adjusting the precipitation parameters (concentration of the reactants, temperature, dielectric constant of the solvents...). Moreover, because they can be decomposed at quite low temperatures $\left(<300^{\circ} \mathrm{C}\right)$, the size and shape of the metallic or oxide particles obtained can retain, to a certain extent, the memory of the initial granulometry and morphology. These decompositions are thus often called pseudomorphous and can create original micro or nanostructures. On the other hand, solid solutions of many oxalates can be obtained, leading to precursors in which the metallic cations are mixed at a molecular level. The homogeneous mixture of cations at this very fine scale is favorable to the preparation of alloys or mixed oxide at moderate temperature. The powders issued from oxalates decomposition have then been studied and often patented, for a lot of technological applications such as catalysis $[10,11]$, sorption of pollutants [12], support of solid oxide fuel cells [13], energy storage [14-16], magnetic recording [17-19], inert anode for aluminum electrolysis [20] and low temperature solders [21, 22]. For this last application, silver or copper oxalates are decomposed below $300{ }^{\circ} \mathrm{C}$ to weld metallic parts. Because silver is a noble metal, the decomposition of its oxalate in air, leads directly to metallic silver. To obtain pure metallic copper is however better to carry out the decomposition under inert or reducing atmosphere but, as for silver oxalate, the transformation of the oxalate into a metal is easy and require few energy [23, 24]. Selective laser decomposition of oxalate films is then an interesting way to create metallic patterns on various substrates. Transparent electrodes made by this process, seem however to be one of the most important potential application.

Bibliographical data indeed show the wide technological field for which transparent electrodes are needed. Such electrodes, with quite high electrical conductivity and transparency, are required for optoelectronic devices such as touch panels [25], liquid-crystal displays [26], solar cells [27] and light emitting diodes [28]. For the designers of original electronic devices, they can also be basic elements for electronic systems incorporating transparent energy storage [29-31], gas sensors [32] or heaters [33] devices.

For some of the previous applications, transparent electrodes must be obtained on large areas on flexible substrates. Moreover, to ensure the competitiveness, the cost of the materials and the process required for the manufacturing, have of course, to be as low as possible. The indium tin oxide films, which are for now the most used transparent semi-conductors but which are very costly, are increasingly difficult to fill these specifications. Moreover, the availability of indium in the earth crust is low and mining of this element at an acceptable price could end in the next ten years. There is then an intensive quest of new materials and new simple process to prepare conductive and transparent films on large surfaces [34]. 
The most promising materials seems to be graphene [35], carbon nanotubes [36], organic thin films [37], very thin metallic layers [38, 39] and random or organized metallic networks. Random networks are generally obtained using metallic nanowires, especially silver nanowires [40]. To improve the electrical contacts between the nanowires, a heat treatment is generally required. But as a low laser power [40] or a short flash of light [41] is necessary to ensure particles welding, polymer substrates can be implemented. After laser annealing, nanowires random networks can have a transparency in the visible range, close to $90 \%$ and a resistivity around few ohms per square [40]. Other mechanical or chemical methods [42] can improve the electrical properties of the metallic random networks making them serious candidates as conductive and transparent materials for flexible electronic systems. Silver or copper nanowires can be deposited by several techniques such as drop casting, spin coating, spray deposition, Meyer rod coating or inkjet printing which are described in a synthetic way by Ye et al. [42].

Ink jet printing makes possible the manufacture of periodic patterns or grids capable of conducting electrical current while minimizing optical absorption [43, 44]. The minimal size of such patterns is however limited by the printing technique at about $100 \mu \mathrm{m}$. Due to this quite big size, eye can detect the optical contrast between the metallic components and the transparent substrate. For the so-called gravure printing process [45], a suspension of nanowires is deposited by the doctor blade technique on an engraved matrix. The nanowires that filled in the trench pattern are then transferred onto a transparent film wrapped around a roller. But the minimal size of the patterns seems also limited to few hundred micrometers [45].

Other simple patterning methods such as screen printing $[46,47]$ of metallic nanoparticles or metallic salts, suffers from the same problem. Different strategies, taking advantage of lithography-like processes, have then been implemented to create patterns with smaller sizes. Grids with submicronic wires can be made from silver films by direct laser interference patterning [48]. The periodic spots of light ablate locally the silver, leaving a metallic grid around. A first step of silver film preparation, by thermal evaporation under vacuum, is however required and a high power laser source is also necessary. Grids with wires of several few to tens micrometers have been obtained using capillary, coffee-ring or magnetic effects on drops of inks of metallic nanoparticles or hybrid silver-magnetite nanowires [49-51]. For these techniques, a mask by photolithography manufacturing is however required. Self-assembled polymer microspheres were used as a mask through which were deposited metallic nanoparticles or thin films. After removing the microspheres, metallic lattices made of submicronic wires, were obtained [52, 53]. Another way is to deposit a metallic film on a cracked polymer template [54]. After removing the polymer, the metal deposited in the bottom of the cracks makes a conductive network with micronic wires. All of these processes are multi-step methods. Hong et al. [55] proposed the simplest method, which allows grids made of fine wires of approximately $10 \mu \mathrm{m}$. For this maskless method, a silver nanoparticles ink is spin coated onto a glass or polymer transparent substrate covered by layer of grip. A Nd:YAG laser $(\lambda=532 \mathrm{~nm})$ is then focused and scanned on the silver nanoparticles to convert them into an electrical conductive track. It was demonstrated that a laser power close to $50 \mathrm{~mW}$ is enough to sinter the silver nanoparticles. Their nanometric size (approx.10 nm) favors their sintering according to Gibbs-Thomson equation for the particles, which specifies the decrease of the melting point with their size. Zhou et al. [56] also used a direct writing method based on the interaction between a $405 \mathrm{~nm}$ laser and an ink 
consisting of a mixture of silver nitrate, sodium citrate and polyvinylpyrrolidone (PVP). Chemical complexing and reduction reactions were involved. A very good adhesion of the silver pattern on the polycarbonate substrate was observed due to the PVP use and lines of $200 \mu \mathrm{m}$ wide were revealed.

In this paper, another direct and simple method of preparation of fine metallic grids is proposed and studied. This method, based on a local laser decomposition of the metallic precursor, takes benefit of the low decomposition temperature of silver oxalate into metallic nanoparticles, which have a high propensity to sintering [21] because of their melting points lowered relative to the bulk state [57-59]. This new process is, by way of example, applied to the production of transparent electrodes on a polycarbonate substrate. The characterization of the silver patterns thus obtained, makes it possible to reveal their specificities and to better understand their mechanisms of formation and sintering, during the process implemented.

\section{Experimental}

\section{Preparation of Powders, Suspensions and Layers of Silver Oxalate}

Silver oxalate was obtained by chemical precipitation by reacting silver nitrate (Ag$\left.\mathrm{NO}_{3}\right)$ with ammonium oxalate $\left(\left(\mathrm{NH}_{4}\right)_{2} \mathrm{C}_{2} \mathrm{O}_{4}, \mathrm{H}_{2} \mathrm{O}\right)$. The silver nitrate was dissolved at a rate of 2 moles per liter, in a solution containing $50 \%$ by volume of water and $50 \%$ of ethylene glycol. It was poured dropwise into a $0.3 \mathrm{M}$ aqueous solution of ammonium oxalate. The use of a hydro-alcoholic medium and a dropwise addition makes it possible to precipitate oxalate particles having a quite narrow particle size distribution and controlled sizes. This methodology of elaboration is inspired by previous works [18-21]. The precipitate formed was separated from the mother liquors by filtration and then washed extensively in order to remove the nitrate and ammonium ions.

The silver oxalate was subsequently mixed in isopropylic alcohol at $25 \%$ mass of oxalate per $75 \%$ mass isopropylic alcohol. The suspensions were vigorously shaken and sonicated to avoid aggregates. The oxalate particles, however, tend to sediment over time so that fast use of the suspension (less than one hour after dispersion of the particles in the liquid) is preferable, to keep a homogeneous product and to make reproducible experiments.

Silver oxalate layers were deposited on transparent polycarbonate substrate, using the spin coating technique. Drops of a total volume of $0.3 \mathrm{~cm}^{3}$ of the previous suspension were deposited on a SPIN 150 wafer spinner rotating at a typical speed of $500 \mathrm{rpm}$. The deposits were dried under vacuum at a room temperature in a lyophilizer Christ Alpha 2-4 LSC plus. Deposits made generally, had surfaces of $2.5 \times 2.5 \mathrm{~cm}^{2}$ and a thickness close to $50 \mu \mathrm{m}$ after drying. Since silver oxalate is sensitive to high daylight exposure, precipitates, suspensions and films have then been stored in opaque containers or cans and thus can be used for several months.

\section{Selective Laser Decomposition of Oxalate Deposit}

A Dilase 250 equipment from Kloe has been used to locally expose oxalate deposits to a focused light beam. Dilase 250 is a photolithographic machine equipped with a solid 
laser source emitting a blue radiation of $405 \mathrm{~nm}$ wavelength with a maximal power of $300 \mathrm{~mW}$. The diameter of the spot focused on the surface of the sample, was close to 5 $\mu \mathrm{m}$. The machine is equipped with a motorized XY motion system to describe simple or complex geometries previously programmed on its design software, with a precision of the order of $0.1 \mu \mathrm{m}$. The sample, maintained by a suction system on the XY motorized sample holder, was moved with a scanning speed of 6 to $6000 \mathrm{~mm} / \mathrm{min}$.

The blue laser was chosen among the solid lasers, which can be integrated into "conventional" photolithography machines. It was also selected for its ability to present a good power (a few hundred milliwatts) to allow not only the decomposition of silver oxalate, but also that of other more stable oxalates, requiring higher temperatures. The wavelength was chosen in the optical absorption domain of silver oxalate and various other oxalates, more specifically retaining a wavelength short enough, to limit diffraction phenomena and have a laser spot small size. The optical system used, has also a large depth of field, making it possible to easily decompose the oxalate through a transparent substrate.

For the experiments carried out, the laser beam passed through the transparent substrate and was focused at the substrate-oxalate interface. This configuration was preferred to a direct exposure of the oxalate to the light, for several reasons. Upon arriving through the substrate, the laser encounters a flat oxalate surface with a very low roughness, which is essentially defined by the characteristics of the substrate. The laser spot can thus be precisely focused. The opposite surface of the oxalate deposit is less regular and less smooth and it does not offer such a well-defined focus plan. In addition, the beam is gradually absorbed as it enters the oxalate. This implies that the maximum energy is provided, for the chosen configuration, to the substrate-oxalate interface. This is generally beneficial because a high laser power improves the bond between the silver formed by the decomposition of the oxalate and its polymer support. The gradual absorption of the laser beam means also that beyond a given thickness depending on its power, the oxalate is only very slightly decomposed, or even devoid of any modification. To keep only the silver patterns formed by laser exposure, the nonexposed oxalate is dissolved in a final step by a concentrated ammoniacal solution ( $>$ $2 \mathrm{M}$ ) then rinsed with deionized water. This step therefore also has the effect of eliminating the weakly or not decomposed oxalate particles, situated directly above the silver patterns, on the side opposite the substrate. The thickness of the correctly sintered silver patterns, is thus only fixed by the power of the beam, if it is assumed that the layers of oxalate deposited have a constant densification. This thickness, significantly smaller than that of the oxalate initially deposited, has the advantage of being very homogeneous for all of the silver patterns formed and independent of the spin coating process, which is not always easy to control.

To improve the compactness of the metallic wires, samples were sometimes pressed under 3 to $5 \mathrm{MPa}$ uniaxial pressure with a Specac hydraulic press, after laser insolation.

\section{Characterization and Measurements}

The behavior of the silver oxalate during heating was analyzed by thermogravimetric and differential thermal analysis using a Setaram TAG 92. The crystalline structure of the samples before and after laser decomposition was studied using Bruker AXS D4 Endeavor diffractometer equipped with a 1D LynxEye detector. $\mathrm{K} \alpha$ radiations $\left(\lambda_{\mathrm{K} \alpha 1}=\right.$ 
$0.15405 \mathrm{~nm}$ and $\lambda_{\mathrm{K} \alpha 2}=0.15443 \mathrm{~nm}$ ) emitted by a copper anode, were used as X-ray source. The $\mathrm{K}_{\beta}$ ray was eliminated by a nickel filter. The microstructure of the samples and the patterns written by the laser, were observed by optical (Optical numerical microscope VHX-S50 from Keyence) and scanning electron (Jeol JEM 6700F field emission gun) microscopes. The composition of oxalate and metal deposits was analyzed by Energy Dispersive Spectrometry (EDS) with a Princeton Gamma Tech detector on the JSM 6700F microscope. A focused ion beam (SEM/FIB FEI Helios 600i) was used to prepare cross-section for characterization by scanning electron microscopy of the vertical planes of the laser insolated oxalate layers. The roughness and thicknesses of the oxalate deposits were measured by optical profilometry (S-Neox Sensofar). The optical properties of the patterned samples were analysed by a Bentham PVE 300 photovoltaic characterization system, with integrating operation mode. The electrical conductivity measurements were carried out on an electrical current-voltage test bench comprising a 4 probe station Suss PA 200 coupled to a high speed DC parameters measurements Agilent 4142B and driven by a Metrics IC S software. The measuring bench allows both 2 and 4 probe measurements.

\section{Results and Discussion}

\section{Powders, Suspensions and Layers of Silver Oxalate}

As revealed by $\mathrm{X}$-ray diffraction and scanning electron microscopy, polyhedral $\mathrm{Ag}_{2} \mathrm{C}_{2} \mathrm{O}_{4}$, silver oxalate particles of average size close to 3 microns, were obtained. The X-ray diffractogram and the morphology of the particles are given in Fig. 1.

The thermogravimetric analysis under air (Fig. 2) shows a mass loss of about $29 \%$ at $250{ }^{\circ} \mathrm{C}$, close to the theoretical value corresponding to the decomposition of the silver oxalate into metallic silver and carbon dioxide, according to the following chemical reaction (Eq. 1):

$$
\mathrm{Ag}_{2} \mathrm{C}_{2} \mathrm{O}_{4} \rightarrow 2 \mathrm{Ag}+2 \mathrm{CO}_{2}
$$
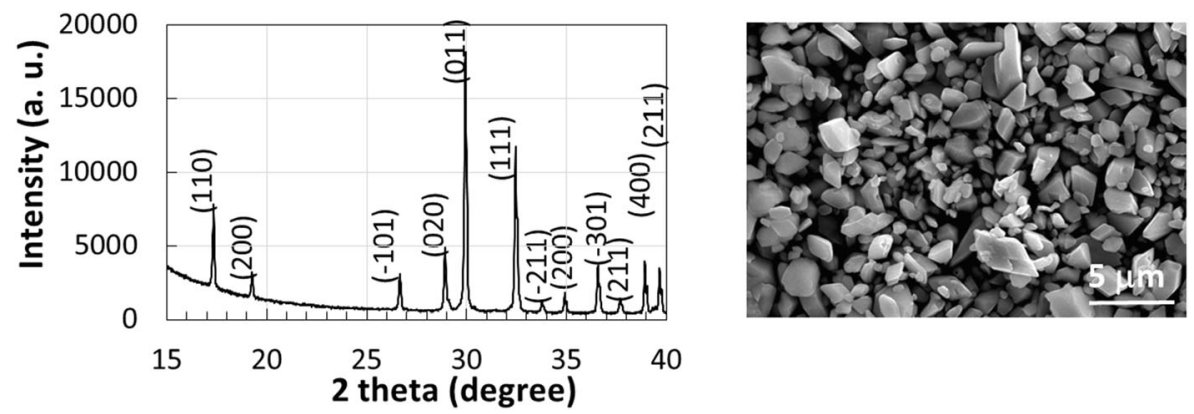

Fig. 1 X-ray diffraction pattern (peaks were indexed using the JCPDS $\left(\mathrm{Ag}_{2} \mathrm{C}_{2} \mathrm{O}_{4}\right)$ 00-022-1335 file) and scanning electron microscopy image of silver oxalate particles prepared by reacting silver nitrate and ammonium oxalate 


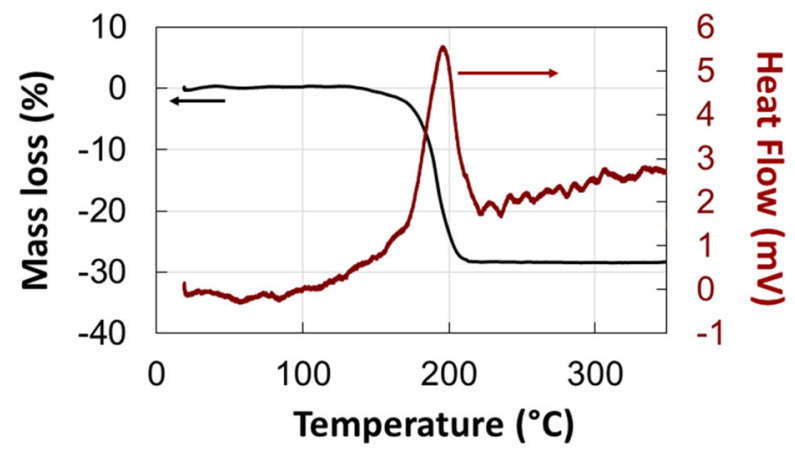

Fig. 2 Thermogravimetric and differential thermal analysis, under air flow, of $\mathrm{Ag}_{2} \mathrm{C}_{2} \mathrm{O}_{4}$

This reaction is highly exothermic as demonstrated by the exothermic peak revealed by differential thermal analysis (Fig. 2).

The silver oxalate deposits on polycarbonate substrates, prepared by the method described in the experimental part 2.1, consist of a low compact assembly of particles whose roughness $\mathrm{Ra}$ is $1.5 \mu \mathrm{m}$. The density of the deposit on polycarbonate substrate, is close to $0.5 \mathrm{~g} / \mathrm{cm}^{3}$ thanks to the measurement of its thickness $\left(50.10^{-4} \mathrm{~cm}\right)$, its surface $\left(2.5 \times 2.5 \mathrm{~cm}^{2}\right)$ and its mass (around $\left.15.10^{-3} \mathrm{~g}\right)$. Compared with the real density of silver oxalate $\left(\mathrm{d}_{\left(\mathrm{Ag}_{2} \mathrm{C} 2 \mathrm{O} 4\right)}=5 \mathrm{~g} / \mathrm{cm}^{3}\right)$, the relative density of the deposit is therefore close to $10 \%$. This low compaction ability is also consistent with the apparent relative density of the silver oxalate powder which is evaluated at $10 \%$.

The total decomposition of the oxalate at the minimal required temperature $\left(250{ }^{\circ} \mathrm{C}\right)$ cannot be done when deposited on layers or substrates made of polymers, because of the low $\mathrm{Tg}$ or thermal stability of such materials. Decomposition can be done however at $250{ }^{\circ} \mathrm{C}$ on oxalate deposited on glass substrate $\left(2.5 \times 2.5 \mathrm{~cm}^{2}\right.$ surface) (Fig. 3a). The use of glass or polycarbonate substrates does not modify the microstructure of silver oxalate deposits by spin coating. So, in the case of silver oxalate layer on glass substrate, the decomposition, in a conventional furnace, essentially results in a decrease in the thickness of the deposit from $50.10^{-4} \mathrm{~cm}$ to $15.10^{-4} \mathrm{~cm}$ and mass loss consistent with previous thermogravimetric analysis. The mass of metallic silver constituting the film after heat treatment thus being $11.4 .10^{-3} \mathrm{~g}$, it follows that its relative density is of the order of $12 \%$ (density of pure and dense silver $=10.49 \mathrm{~g} / \mathrm{cm}^{3}$ ). The error on this rough evaluation is $\pm 2 \%$. It is relatively important, but it gives an idea of the porosity of silver resulting from the decomposition of oxalate, which seems in quite good agreement with the very porous layer of silver observed by scanning electron microscopy (Fig. 3b). This type of metallic foam has already been observed by other authors [60], on metallic silver resulting from the decomposition of small oxalate particles using a spark plasma sintering device.

\section{Patterned Silver Oxalate Layers}

These oxalate deposits, on polycarbonate substrates, were subsequently processed by the laser spot of the photolithography machine, at a given scanning rate, according to a one-line pattern. For each laser insolation, the light power measured at the surface of the deposit has been set to values between 3 and $100 \mathrm{~mW}$. Exposure to the focused 

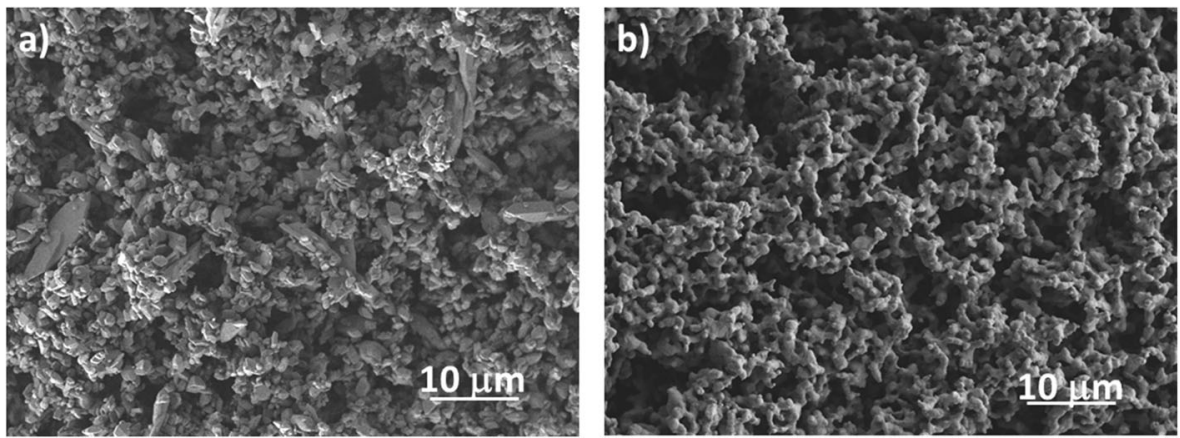

Fig. 3 Scanning electron micrographs of a silver oxalate deposit on a glass substrate (a) and after decomposition into metallic silver at $250{ }^{\circ} \mathrm{C}$ in air for $15 \mathrm{~min}$ in a conventional furnace (b)

laser beam causes the local transformation of oxalate into metallic silver for laser powers from $3 \mathrm{~mW}$ upwards (Fig. 4a).

Silver oxalate is like various salts of this metal, sensitive to light and can therefore be the site of photochemical decomposition [24]. This is, however, slow and when the oxalate is brought to a high temperature by the absorption of an optical beam of high energy density, photo-thermal decomposition largely predominates. In addition, the reaction is supported by its exothermic character. For this reason, the reaction can spread uncontrollably well beyond the size of the light spot, in the case of too high laser powers.

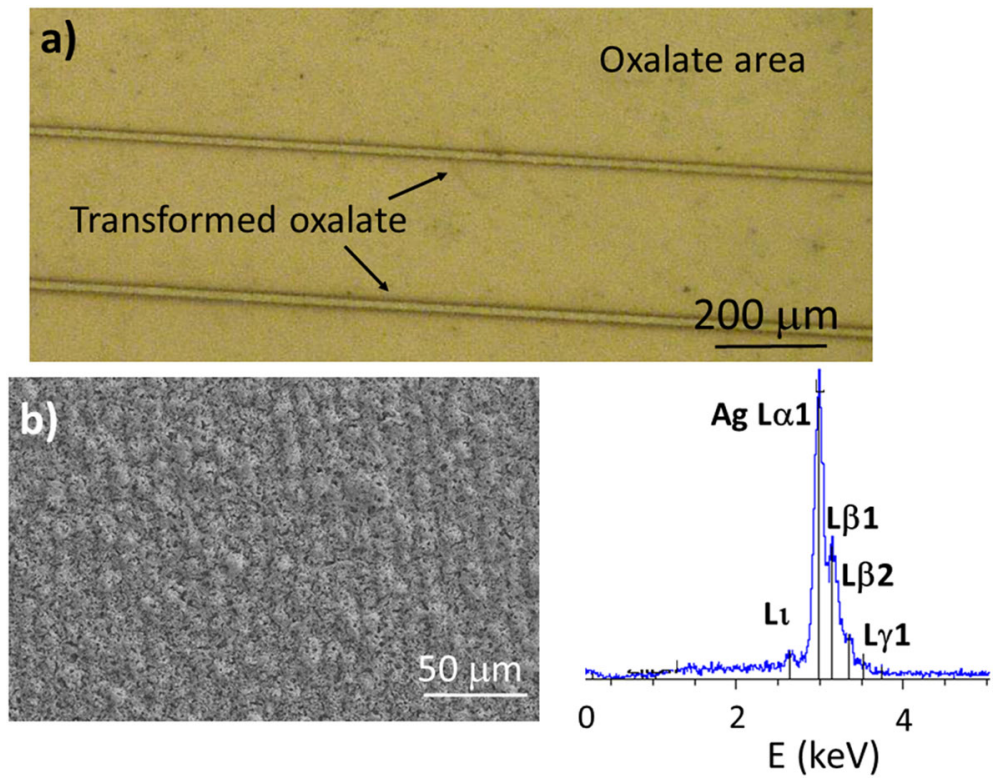

Fig. 4 Two examples of the transformation of oxalate into metallic silver. Optical image of two separated fine lines of insolated oxalate with a $3 \mathrm{~mW}$ power (a), scanning electron micrograph and corresponding EDS analysis of oxalate deposit exposed through the substrate, to a $20 \mathrm{~mW}$ laser power with a pattern of contiguous lines spaced $10 \mu \mathrm{m}$ apart on a large area, after dissolution of non-insolated oxalate with an ammonia solution (b). The sample scanning speed was $120 \mathrm{~mm} / \mathrm{min}$ for a) and b) 
It is important to emphasize that the method implemented has the advantage of leading to the formation of sintered metallic silver, at the end of the photothermal decomposition, even when it is carried out in air. The metallic state is in fact for silver, a stable state in the vicinity of normal thermodynamic conditions. No addition of reducing chemical compounds is necessary, unlike other processes used for other metals [61].

Scans spaced $10 \mu \mathrm{m}$ apart, make it possible to obtain contiguous transformed lines and to produce totally exposed surfaces of sufficient size to perform different analyses (Fig. 4b). This design used for EDS analysis or X-ray diffraction reveals, after removing the non-insolated oxalate with an ammonia solution, that the product formed is metallic silver, as in the case of thermal decomposition in a conventional furnace. Indeed, the EDS spectrum presented in Fig. $4 \mathrm{~b}$ does not reveal any X-ray peaks characteristic of the carbon and oxygen elements present in the oxalate. Only the silver element peak is observed, attributed to the presence of metallic silver in accordance with the X-ray diffraction pattern in Fig. 5. A mean crystallite size was then estimated at $40 \mathrm{~nm}$ using the Scherrer equation (Eq. 2) applied to the main X-ray diffraction peak:

$$
\mathrm{D}=0.9 \lambda /(\mathrm{FWHM})_{(2 \theta)} \cos \theta
$$

where D is the crystallite size, $\lambda$ the wavelength of the radiation (nm), FWHM ${ }_{(2 \theta)}$ the full width of the diffraction peak and $\theta$ the diffraction angle (rad). The crystallite size is smaller than that obtained by a heat treatment at $250{ }^{\circ} \mathrm{C}$ for $15 \mathrm{~min}$ in a furnace, which is close to $75 \mathrm{~nm}$. Due to the short material-laser interaction time, decomposition is very rapid and the gas evolution, which accompanies it, acts as a pore-forming agent in accordance with literature [60]. The sintering of silver crystallites is thus hindered.

Given the brevity of the laser exposure, this observation reflects a quiet strong local heating of oxalate by the laser beam. This is due to the partial absorption of the laser power by the oxalate $(35 \%$ at $405 \mathrm{~nm})$, but also to the additional heat resulting from its very brief and exothermic decomposition. For polycarbonate substrates, short and local

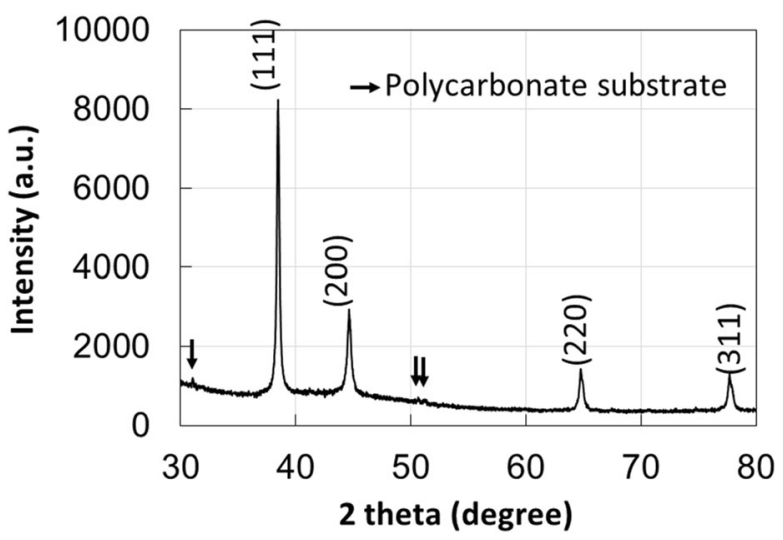

Fig. 5 X-ray diffraction pattern of silver obtained after laser insolation of oxalate deposit with a laser power of $5 \mathrm{~mW}$ and a scanning speed of $120 \mathrm{~mm} / \mathrm{min}$. The small peaks indicated by arrows correspond to the diffraction of the polycarbonate substrate 
heating avoids the deterioration of the entire substrate. It also has the advantage of making a local and superficial melting of the substrate, to the right of the zones converted into metallic silver, and to stick these last on their support. Figure 6 shows an example of the partial rooting of the metal in the polymer following its partial melting. Given the difficulties encountered in ensuring good adhesion of the silver formed on the glass alone and with a view to potential technological applications rather targeted on flexible electronics, the following experiments were then conducted on flexible substrates, mainly polycarbonate.

In order to explore and understand more precisely the phenomena involved in the decomposition of silver oxalate by a laser spot, specific experiments were carried out on a one-line pattern and a single laser exposure. First experiments consisted in plotting lines of silver having a thickness from 2 to $10 \mu \mathrm{m}$ and width from 10 to $100 \mu \mathrm{m}$ depending on the insolation conditions. The laser spot used, had a power from 3 to $100 \mathrm{~mW}$. Its relative movement, with respect to the sample, took place at a speed chosen between 60 and $600 \mathrm{~mm} / \mathrm{min}$. This speed range avoid prohibitive exposure times, when making large samples, and not pushing the machine near its limits for the highest speeds. The results of the experiments, are illustrated on Fig. 7, which shows the silver particles observed after laser exposure and removal of non-decomposed oxalate.

Whatever the previous experimental conditions, the oxalate is partially or totally decomposed. For a speed of $120 \mathrm{~mm} / \mathrm{min}$ and mild conditions (laser power from 3 to $20 \mathrm{~mW}$ ), the decomposition is partial (Fig. 7a). The initial polyhedral shape of oxalate particles is kept showing a pseudo-morphous decomposition. For the experimental conditions used, the sintering of the silver grains formed within the oxalate particles is indeed very low. The same is true for the sintering of silver grains from adjacent oxalate particles. High porosity is also observed within the particles. This is created by the departure of carbon dioxide resulting from decomposition (see reaction 1) and the removal, before observation, of the remaining oxalate. This partial decomposition was also illustrated by the local laser treatment of deposit made with another oxalate, based on acicular particles (Fig. 8) but with a similar medium size than the polyhedral oxalate particles. Porous particles clearly appeared in the well-limited zone where the laser was focused. For the polyhedral studied oxalates, only the higher powers ( $26 \mathrm{~mW}$ or more) allow a total decomposition with growth and coalescence of silver grains and the
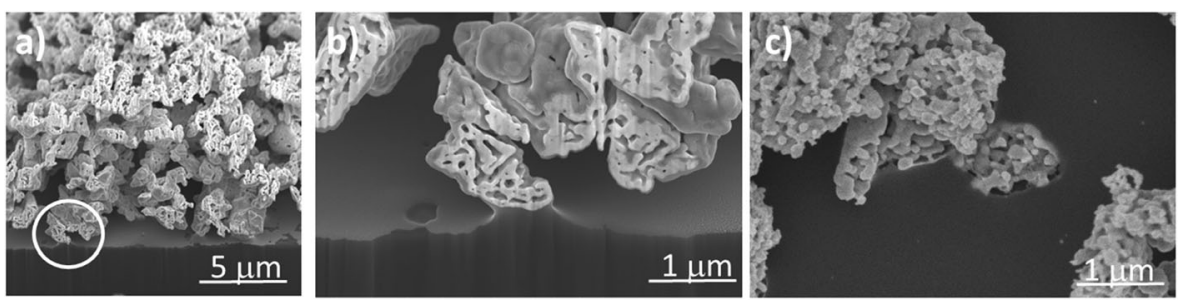

Fig. 6 Scanning electron micrograph of a cross section (a), (b) and a surface (c) of silver strip partially rooted in a polycarbonate substrate after laser beam exposure (laser power of $14 \mathrm{~mW}$ for a and $\mathrm{b}, 5 \mathrm{~mW}$ for c, a $120 \mathrm{~mm} / \mathrm{min}$ scan speed for the whole) and after removing the oxalate remaining outside the exposed areas 

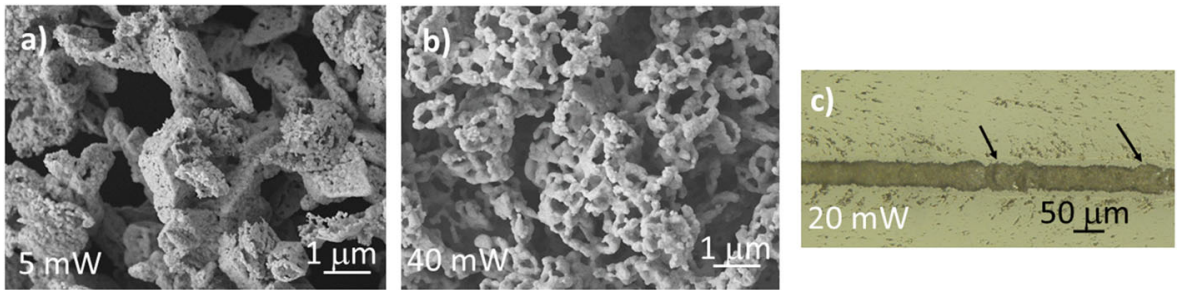

Fig. 7 Scanning electron micrography of the surface of silver lines after laser insolation with a $5 \mathrm{~mW}$ (a) and $40 \mathrm{~mW}$ (b) power showing respectively partial and total decomposition. Optical micrography (c) is an example of uncontrolled reaction, which leads to silver deposit outside the insolated line due to a runaway from thermal decomposition on the one hand and irregularities and undulations on the silver lines on the other hand. The non-insolated oxalate was removed before the observations. The arrows indicate the areas where the uncontrolled decomposition of the oxalate has caused deformations on the silver lines

creation of a vermicular silver pattern (Fig. 7b) similar to that observed with the conventional heat treatment previously carried out (Fig. 3).

As previously stated, the decomposition of silver oxalate is highly exothermic and produces a large amount of gas evolution. For these reasons, its decomposition is explosive when strongly heated very suddenly. The amount of silver oxalate subjected to decomposition also plays an important role. The higher it is, the more the probability of explosion increases. High laser powers therefore very likely produce small local explosions that volatilize the particles or whose heat generated can propagate decomposition on both sides of the line of displacement of the laser beam. The same result is observed with high speed of movement. For a given time, a greater quantity of material than at low speeds, is in fact subjected to decomposition. This situation facilitates the runaway of the reaction and generally leads to local explosions. Irregular lines are then formed (Fig. 7c).

After dissolving the oxalate unexposed to the laser spot, more or less continuous silver wires remain attached to the polycarbonate substrate. For the most favorable laser insolation conditions (laser power from 3 to $14 \mathrm{~mW}$ and scanning speed of $120 \mathrm{~mm} /$

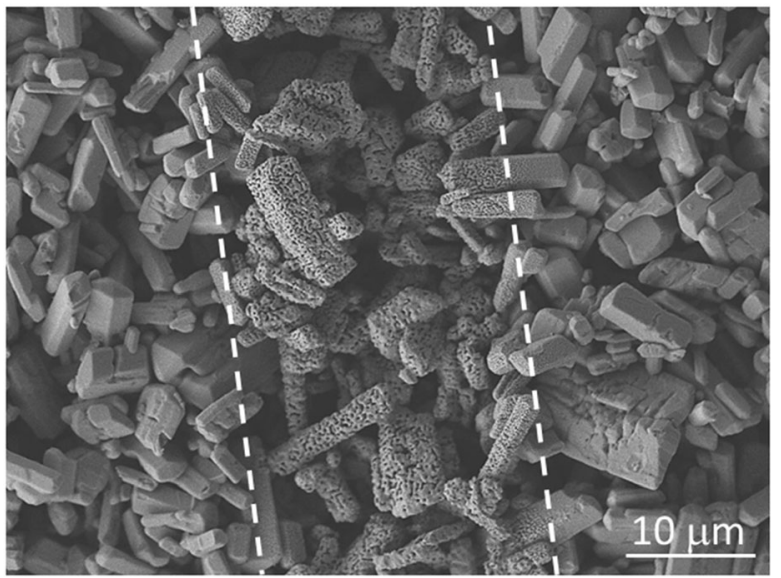

Fig. 8 Scanning electron micrograph of an oxalate deposit exposed to laser spot $\mathrm{P}=5 \mathrm{~mW}, \mathrm{v}=120 \mathrm{~mm} . \mathrm{min}^{-}$ 
$\mathrm{min}$ ), the silver lines consist of connected filaments. For laser power from 3 to $14 \mathrm{~mW}$, their width and thickness increase from 10 to $30 \mu \mathrm{m}$ and 2 to $10 \mu \mathrm{m}$ respectively.

The finest lines obtained, of the order of $10 \mu \mathrm{m}$, which did not always ensure good electrical conductivity, demonstrate the effects of thermal diffusion during laser irradiation. The estimated diameter of the spot is in fact only $5 \mu \mathrm{m}$. The use of femtosecond lasers could potentially improve the fineness of the silver patterns inscribed by our process. Using a different method, however, Son et al. [62] have indeed obtained metal patterns of $300 \mathrm{~nm}$, thanks to the use of ultra fast lasers. There is here an interesting and promising avenue of progress, even if the advantage of our current process lies, however, in the use of less expensive light sources, which can be integrated into conventional photolithography machines having, moreover, a great depth of field.

During the decomposition, the removal of the carbonaceous part of the oxalate molecule and the partial sintering of the formed silver metal, necessarily result in a decrease in volume. In addition, the removal of particles located at the free surface, that is to say on the opposite side to the entry of the laser beam into the deposit, is also added to this decrease in volume during the dissolution of the oxalate (see 2.2.). The laser arrives indeed by the transparent substrate. It is therefore gradually absorbed when it penetrates and transforms the oxalate layer. Particles near the free surface thus receive less light energy. They are then incompletely decomposed or less strongly bound with the core of the wire and can be removed during the dissolution and washing of the residual oxalate.

The compactness of the silver wires is low as observed on Figs. 6 and 7, even for high laser power $(40 \mathrm{~mW})$. To improve the compaction and sintering of silver particles, various additional tests have been carried out. However, since microscopic observation does not always allow the effects of changes in laser exposure conditions to be appreciated, specific samples have been developed to measure their electrical resistance. Thus a $10 \mathrm{~mm} \times 10 \mathrm{~mm}$ lines network with a pitch of $500 \mu \mathrm{m}$ was defined (Fig. 9). This type of sample was used to measure the electrical resistance between the two lateral electrodes. According to the previous characterizations, a laser power of $5 \mathrm{~mW}$ is chosen for a one-time insolation. It allows a trade-off between an electrical conductivity and silver lines fine enough to favor optical transparency.

First of all, successive laser exposure with a power increase for each insolation, to avoid uncontrolled decomposition, have been tested. An increase of the width of silver lines is observed due to the use of higher laser power and probably too, because decomposition tends to spread laterally. The scanning electron microscopy characterization shows no significant difference in the surface microstructure (Fig. 10) but the electrical resistance, measured with a multimeter between the two electrodes, decreases from $130 \Omega$ for a $5 \mathrm{~mW}$ laser insolation (Fig. 10a) to $80 \Omega$ for 5 laser expositions (Fig. $10 \mathrm{~b})$. This could be the result of a higher rate of decomposition into metallic silver and better sintering of the metal particles together.

This electrical resistance is however quite far from that which one might expect in the case of the same pattern made up of perfectly densified silver lines. Indeed, the resistivity of dense silver being $16.10^{-6} \Omega . \mathrm{mm}$, an electrical resistance close to 0.17 ohms for the whole pattern should in fact be reached, if this pattern is made of 21 lines (see Fig. 9) having a mean thickness of $3 \mu \mathrm{m}$ and a width close to $15 \mu \mathrm{m}$. 


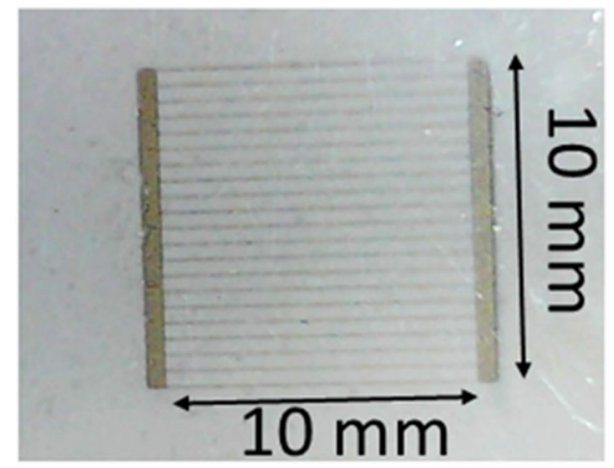

Fig. 9 Network of silver line after laser exposure and removing the non-irradiated oxalate (Power : $5 \mathrm{~mW}$ and scanning speed of $120 \mathrm{~mm} / \mathrm{min}$ )

Irradiation of the oxalate from the side opposite to the substrate does not make it possible to improve the electrical characteristics. The microstructures of the wires are in fact identical, contrary to the observations made by Yeo et al. [63] for another laser process. For the latter, depending on whether the laser arrives through the substrate (bottom focusing) or directly on the precursor to be decomposed (top focusing), an optically absorbent layer is or is not interposed on the light path. This results in a very different heating mode in the two cases. For our process, the oxalate layer itself absorbs the laser beam. Whether the latter arrives directly on the oxalate or through a transparent substrate, the two configurations are similar to that described as "top focusing" by Yeo et al. [63] and the decomposition is carried out in a similar manner. Another way has therefore been tested in an attempt to improve the electrical performance of the wires.

This way is to apply a pressure on the silver wires after one laser insolation at $5 \mathrm{~mW}$ of the silver oxalate and removing the non-transformed material. This was done very
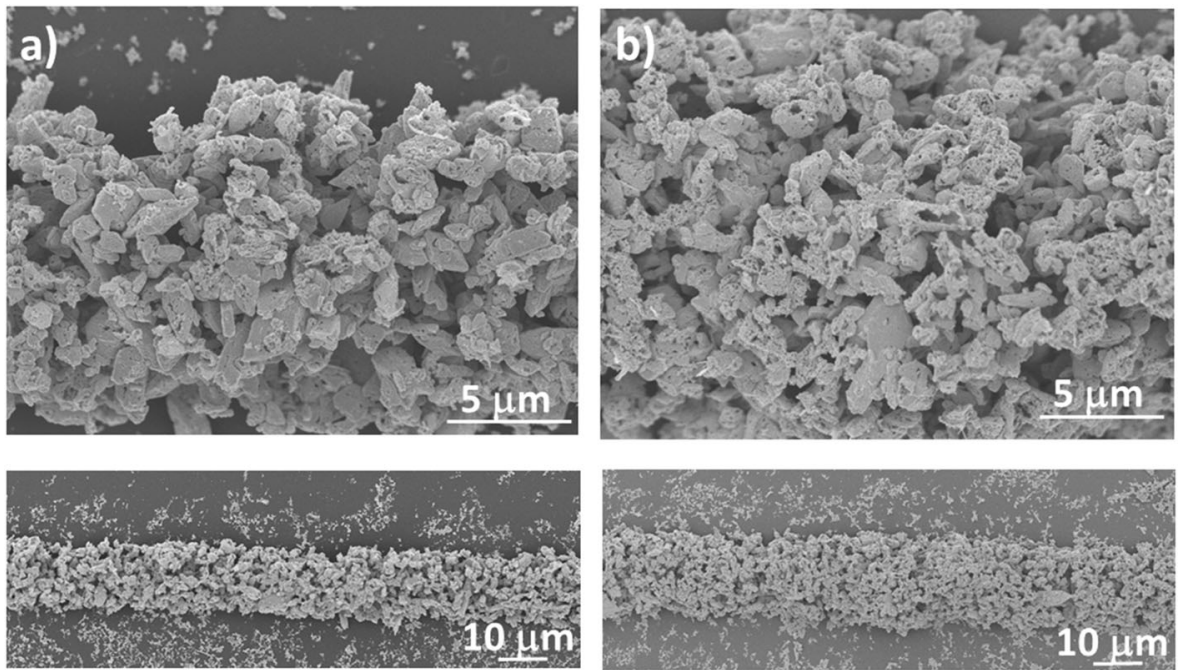

Fig. 10 Top views of scanning electron micrographs of silver wires obtained by successive laser exposures ( $5 \mathrm{~mW}$ one time (a), 2 insolations at $5 \mathrm{~mW}$ and 3 insolations at $8 \mathrm{~mW}$ (b), relative spot speed: $120 \mathrm{~mm}^{\mathrm{min}} \mathrm{m}^{-1}$ ) 
simply, by applying a mirror polished piston in stainless steel to the pattern, using a hydraulic laboratory press. An example is given on Fig. 11 for a pressure close to $3 \mathrm{MPa}$. In this case the electrical resistance decreases strongly, from $130 \Omega$ to $10 \Omega$ after pressure application. Simultaneously, the thickness of the silver threads decreases from a mean value of 3 to $2 \mu \mathrm{m}$ and their width increase slightly as illustrated by Fig. 11. The scanning electron microscope also reveals changes of the surface of the silver lines. They have both a significantly lower porosity and roughness than before pressing.

Using the previously defined conditions (one insolation $5 \mathrm{~mW}$ and $120 \mathrm{~mm} \cdot \mathrm{min}^{-1}$, pressure of $3 \mathrm{MPa}$ ), silver lines spaced of 500 microns were inscribed in polycarbonate substrates on $1 \mathrm{~cm}^{2}$ surfaces. After removal of the residual oxalate by washing and dissolving, a transparent and electrically conductive flexible material, similar to that shown in Fig. 9, is obtained. Its optical transparency (silver wires on polycarbonate substrate) in the visible range is close to $86 \%$ or $95 \%$ without the polycarbonate substrate contribution. The average sheet electrical resistance of each silver line (measured on lines of $16 \mu \mathrm{m}$ width and about $2 \mu \mathrm{m}$ height) is Rsquare $=0.33 \Omega$. Considering the whole patterned sample of $1 \times 1 \mathrm{~cm}^{2}, \mathrm{R}_{\text {pattern }}$ is therefore $10 \Omega$. This value is in agreement with the resistance directly measured between the two electrodes located at the end of the pattern. By taking into account the definition of Haacke of the figure of merit [64], that is Figure of merit $=\left(\text { Transparency }_{(550 \mathrm{~nm})}\right)^{10} / \mathrm{R}_{\text {pattern }}$, we obtain the values of $0.022 \Omega^{-1}$ for the sample as a whole or $0.059 \Omega^{-1}$ if we correct the effect of the substrate.

The optical and electrical performances of the $1 \mathrm{~cm}^{2}$ silver grating on a polycarbonate substrate are comparable to those of ITO as reported by the authors $[42,65,66]$. However, in their review, Lee et al. [66] present different electrodes of metallic networks and underline that the comparison of the transparency, of the electrical resistance as well as of the figure of merit according to Haacke, is difficult
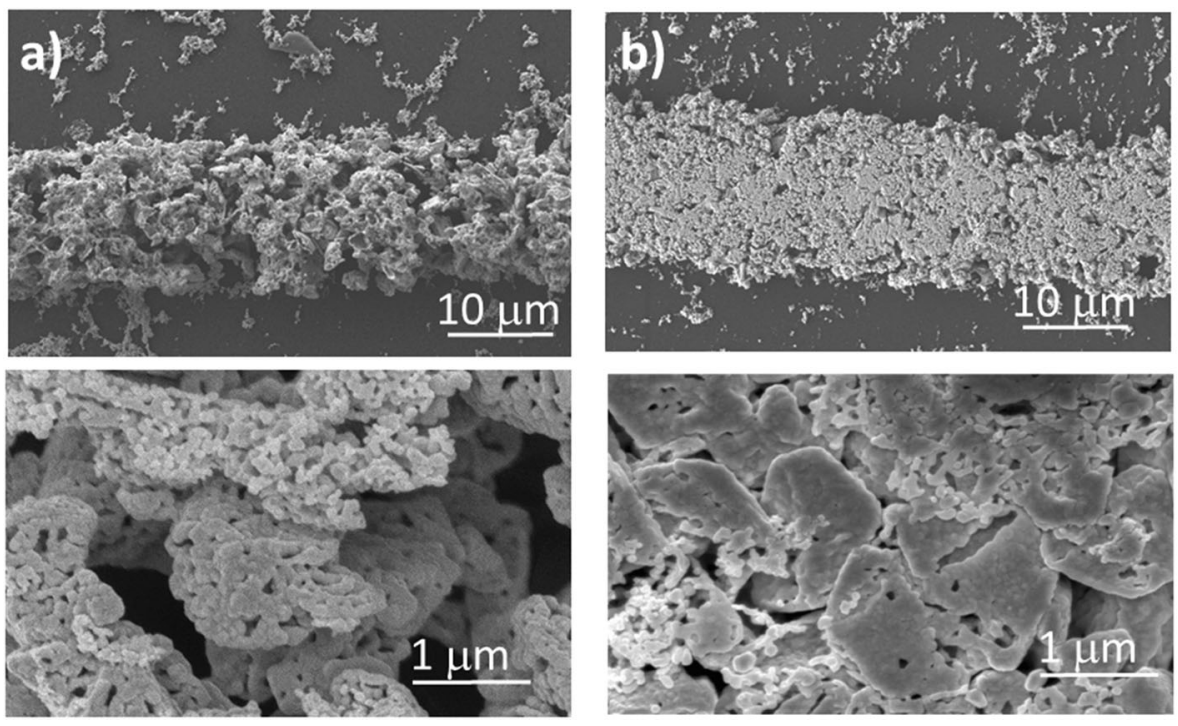

Fig. 11 Scanning electron micrographs of silver wires before (a) and after an applied pressure of $5 \mathrm{MPa}(\mathbf{b})$ 
because of the use of different patterns. The silver network obtained from the selective laser decomposition of oxalate, has in particular very good transparency [65] and it is produced with silver lines having one of the smallest widths described for transparent electrodes based on metal grids except those obtained with femtosecond lasers. These widths are in particular approximately ten times smaller than those obtained by another direct laser writing process, using complex inks based on silver nitrate, sodium citrate and polyvinylpyrrolidone [56].

\section{Conclusion}

The transition metal oxalates are known to be interesting precursors for many technological applications. In this work, however, they are implemented in an original way by a selective laser decomposition process which not only allows an oxalate to be locally transformed into a metal, but also to draw metal patterns with a resolution of a few micrometers.

Given its moderate decomposition temperature $\left(<250{ }^{\circ} \mathrm{C}\right)$, the silver oxalate $\mathrm{Ag}_{2} \mathrm{C}_{2} \mathrm{O}_{4}$ can in fact be reduced, under air, to the metallic silver state by the blue $(\lambda=405 \mathrm{~nm}$ ) focused laser beam (spot size $5 \mu \mathrm{m}$, power used 3 to $100 \mathrm{~mW}$ ) of a photolithography machine. This exothermic reaction requires control of the laser insolation conditions. Thus, thin lines of silver of width close to $15 \mu \mathrm{m}$, for the most appropriate laser exposure conditions, can be directly and easily, formed in a layer of oxalate deposited by spin coating on polycarbonate substrate. Since the metal and the oxalate are of very different chemical natures, it is possible to remove the residual oxalate by an ammoniacal solution without affecting the metal.

The silver conductive lines have a very porous vermicular type microstructure and a relative density of only $12 \%$ compared to the pure, dense silver is achieved. However, this microstructure ensures electrical conductivity but the resistive effects, which result from this not very compact filament organization, can be reduced by simply applying a mechanical uniaxial pressure of $3 \mathrm{MPa}$, perpendicular to the plane of the substrate. This operation irreversibly reduces the porosity, by crushing the strands of silver.

One by one centimeters samples, with an electrical resistance of $10 \Omega$ and an optical transparency of $95 \%$ (after correction of the effects of the substrate) were thus prepared. Such samples are then transparent electrodes with a factor of merit expressed by (Transparency $)^{10} / R_{\text {pattern }}$, close to $0.059 \Omega^{-1}$. This factor of merit at the state of the art, demonstrates the potential of selective laser decomposition to fabricate transparent electrodes.

For the future, different approaches can be considered to better control the thermal decomposition of silver oxalate and possibly lead to more complete sintering of the metal particles obtained. Boldyrev's bibliographic review [24] can at least inspire two. It recalls in fact that prior UV irradiation can in fact increase the rate of decomposition of silver oxalate, by means of a catalytic effect. A first pass of the laser spot with a very low power, on the surface of the particulate film could thus play this role and promote decomposition and sintering during a second irradiation at higher power. The second approach would consist in using particles of sizes different from those which have been used. The literature review shows that thermal decomposition is influenced by the size and shape of the particles. The third way could also be the use of femtosecond laser to reduce the size of the patterns, as has been demonstrated by Son et al. [62]. 
Moreover, given the possibilities offered by digital photolithography machines, the proposed method can easily be used to draw metallic patterns of various shapes and sizes. To its simplicity is therefore added a certain versatility. By extension, this very simple process could also be implemented with other simple or mixed oxalates. For instance, transparent conductors based on copper or other metal and alloy wires, could be achieved under inert or hydrogenated atmospheres. In the same way, simple or complex patterns of oxide type ceramics, could also be printed under ambient air.

Acknowledgements The authors thank Toulouse Tech Transfer for its financial support, V. Gernigon and A. Chapelle for their contribution to the determination of experimental conditions for oxalate deposition by spin-coating, S. le Blond du Plouy and C. Josse from UMS Castaing, Université de Toulouse for their advices, preparation and characterization of the cross-sections. This work was supported by the LAAS-CNRS micro and nanotechnologies platform, member of the French RENATECH network of cleanroom facilities.

Author Contributions The manuscript was written through contributions of all authors. All authors have given approval to the final version of the manuscript.

Funding This work was supported by the Université Toulouse III, the CNRS and Toulouse Tech Transfer.

Data Availability Supporting Information is available from the author.

\section{Compliance with Ethical Standards}

Conflict of Interest No conflicts of interest.

\section{References}

1. Kang, W., Shen, Q.: The shape-controlled synthesis and novel lithium storage mechanism of as-prepared $\mathrm{CuC}_{2} \mathrm{O}_{4}, \mathrm{xH}_{2} \mathrm{O}$ nanostructures. J. Power Sources 238, 203-209 (2013)

2. Liu, T., Shao, G., Ji, M., Ma, Z.: Composite of olive-like manganese oxalate on graphene sheets for super capacitors electrodes. Ionics 20(1), 145-149 (2014)

3. Ang, W.A.E., Yan, L.C., Chui, L.W., Huey, H.H., Srinivasan, M.: One-pot solvothermal synthesis of $\mathrm{Co}_{1-\mathrm{x}} \mathrm{Mn}_{\mathrm{x}} \mathrm{C}_{2} \mathrm{O}_{4}$ and their application as anode materials for lithium-ion batteries. J. Alloys Compd. 638, 324-333 (2015)

4. Liu, X., Jiang, J., Ai, L.: Non-precious metal oxalate microstructures as highly efficient electrocatalysts for oxygen evolution reaction. J. Mater. Chem. A 3(18), 9707-9713 (2015)

5. Singh, S., Chawla, M., Siril, P.F., Singh, G.: Manganese oxalate nanorods as ballistic modifier for composite solid propellants Thermochim. Acta 597, 85-92 (2014)

6. Singh, S., Srivastava, P., Singh, G.: Manganese oxalate nanorods as ballistic modifier for composite solid propellants. J. Ind. Eng. Chem. 27, 88-95 (2015)

7. Kushchevskaya, N.F.: Finely divided Fe-Co-Ni powders made by a thermomechanical method. Powder Metall. Met. Ceram. 35(3-4), 211-212 (1996)

8. Baco-Carles, V., Combes, Ph, Tailhades, Ph, Rousset, A.: New method to prepare iron particles with different morphologies: a way to get high green strength metal compacts. Powder Metall 45(1), 33-38 (2002)

9. Mollard, P., Collomb, A., Devenyi, J., Rousset, A., Paris, J.: Contribution to investigation of fine-particle solid-solutions between cubic iron sesquioxide $\gamma-\mathrm{Fe}_{2} \mathrm{O}_{3}$ and cobalt ferrite $\mathrm{CoFe}_{2} \mathrm{O}_{4}$. IEEE Trans. Magn. 11(3), 894-900 (1975)

10. Bartley, J.K., Xu, C.L., Lloyd, R., Enache, D.I., Knight, D.W., Hutchings, G.J.: Simple method to synthesize high surface area magnesium oxide and its use as a heterogeneous base catalyst Appl. Surf. Sci. 362, 20-27 (2016) 
11. Ye, Y.C., Zhao, Y.T., Ni, L.L., Jiang, K.D., Tong, G.X., Zhao, Y.L., Teng, B.T.: Facile synthesis of unique $\mathrm{NiO}$ nanostructures for efficiently catalytic conversion of $\mathrm{CH}_{4}$ at low temperature. Appl. Catal. B 128, 31-38 (2012)

12. Ma, X.M., Campbell, N., Madec, L., Rankin, M.A., Croll, L.M., Dahn, J.R.: Novel nanoporous $\mathrm{MnO}_{\mathrm{x}}$ (x $=$ similar to 1.75) sorbent for the removal of $\mathrm{SO}_{2}$ and $\mathrm{NH}_{3}$ made from $\mathrm{MnC}_{2} \mathrm{O}_{4} 2 \mathrm{H}_{2} \mathrm{O}$. J. Colloid Interface Sci. 465, 323-332 (2016)

13. Panteix, P.J., Baco-Carles, V., Tailhades, Ph, Rieu, M., Lenormand, P., Ansart, F., Fontaine, M.L.: Elaboration of metallic compacts with high porosity for mechanical supports of SOFC. Solid State Sci. 11(2), 444-450 (2009)

14. Xu, R., Wang, J., Li, Q., Xu, X., Sun, G., Wang, E., Li, S., Gu, J., Ju, M.: Porous cobalt oxide $\left(\mathrm{Co}_{3} \mathrm{O}_{4}\right)$ nanorods: facile synthesis, optical property and application in lithium-ion batteries. J. Solid State Chem. 182(11), 3177-3182 (2009)

15. Yao, X., Xin, X., Zhang, Y., Xu, X.: $\mathrm{Co}_{3} \mathrm{O}_{4}$ nanowires as high capacity anode materials for lithium ion batteries. Alloys Compd. 521, 95-100 (2012)

16. Tailhades, $\mathrm{Ph}$, Carles, V., Rousset, A.: Method of preparing metal powders, metal powders prepared in this way and compacts that include these powders. US Patent 6,464,750 (2002)

17. Deffeyes, R.J., Tyler, W.R.: Acicular metallic powders produced from the organometallic salts. US Patent 4,004,917 (1977)

18. Rousset, A., Salvaing, C., Mollard, P., Manoux, A., Tailhades, Ph: Particulate compositions of ferromagnetic metal oxalates in the form of submicronic acicular particles, the preparation of same and application thereof. US Patent 4,803,291 (1989)

19. Tailhades, $\mathrm{Ph}$, Brieu, M., Mollard, P., Rousset, A., Chassaigne, Y.: High performances boron doped $\gamma-$ $\mathrm{Fe}_{2} \mathrm{O}_{3}$ particles prepared from oxalic precursors. IEEE Trans. Magn. 26(1), 63-65 (1990)

20. Baco, V., Pasquet, I., Laurent, V., Gabriel, A., Tailhades, Ph: Pre paration and electrical properties of dense micro-cermets made of nickel ferrite and metallic copper. Solid State Sci. 11(8), 1503-1506 (2009)

21. Kiryukhina, K., Le Trong, H., Tailhades, Ph, Lacaze, J., Baco, V., Gougeon, M., Courtade, F., Dareys, S., Vendier, O., Raynaud, L.: Silver oxalate-based solders: New materials for high thermal conductivity microjoining. Scr. Mater. 68(8), 623-626 (2013)

22. Vendier, O., Raynaud, L., Baco, V., Gougeon, M., Tailhades, Ph: Process for manufacturing a device comprising brazes produced from metal oxalate. US Patent 9,108, 277 B2 (2015)

23. Pasquet, I., Le Trong, H., Baco-Carles, V., Presmanes, L., Bonningue, C., Baylac, V., Tailhades, P.H., Conedera, V., Calmon, P.F., Dragomirescu, D., Camon, H.: Direct shaping of oxides by laser insolation of transition metal oxalates. J. Eur. Ceram. Soc. 37, 5315-5320 (2017)

24. Boldyrev, V.V.: Thermal decomposition of silver oxalate. Thermochim. Acta 388, 63-90 (2002)

25. Hong, C.H., Shin, J.H., Ju, B.K., Kim, K.H., Park, N.M., Kim, B.S., Cheong, W.S.: Index-matched indium tin oxide electrodes for capacitive touch screen panel applications. J. Nanosci. Nanotechnol. 13, 7756-7759 (2013)

26. Betz, U., Kharrazi Olsson, M., Marthy, J., Escola, F., Atamny, F.: Thin films engineering of indium tin oxide: large area flat panel display application. Surf. Coat Technol. 200, 5751-5759 (2006)

27. Granqvist, C.G.: Transparent conductors as solar energy materials: a panoramic review. Sol. Energy Mater. Sol. Cells 91, 1529-1598 (2007)

28. Sandström, A., Dam, H.F., Krebs, F.C., Edman, L.: Ambient fabrication of flexible and large-area organic light-emitting devices using slot-die coating. Nat. Comm. 3, 1002 (2012)

29. Yang, Y., Jeong, S., Hu, L., Wu, H., Lee, S.W., Cui, Y.: Transparent lithium-ion batteries. Proc. Natl. Acad. Sci. USA 108, 13013-13018 (2011)

30. Jung, J.H., Karimi, M.B., Hahm, M.G., Ajayan, P.M., Jung, Y.J.: Transparent, flexible supercapacitors from nano-engineered carbon films. Sci. Rep. 2, 773 (2012)

31. Chen, T., Xue, Y., Roy, A.K., Dai, L.: Transparent and stretchable high-performance supercapacitors based on wrinkled graphene electrodes. ACS Nano 8, 1039-1036 (2014)

32. Choi, H., Choi, J.S., Kim, J.S., Choe, J.H., Chung, K.H., Shin, J.W., Kim, J.T., Youn, D.H., Kim, K.C., Lee, J.I., Choi, S.Y., Kim, P., Choi, C.G., Yu, Y.J.: Flexible and Transparent Gas Molecule Sensor Integrated with Sensing and Heating Graphene Layers. Small 10(18), 3685-3691 (2014)

33. Im, K., Cho, K., Kwak, K., Kim, J., Kim, S.: Flexible transparent heaters with heating films made of indium tin oxide nanoparticles. J. Nanosci. Nanotechnol. 13, 3519-3521 (2013)

34. Kulkarni, G.U., Kiruthika, S., Gupta, R., Rao, K.D.M.: Towards low cost materials and methods for transparent electrodes. Current Opinion in Chemical Engineering 8, 60-68 (2015)

35. Wang, X., Zhi, L., Müllen, K.: Transparent, conductive graphene electrodes for dye-sensitized solar cells. Nano Lett. 8, 323-327 (2007) 
36. Hecht, D.S., Heintz, A.M., Lee, R., Hu, L., Moore, B., Cucksey, C., Risser, S.: High conductivity transparent carbon nanotube films deposited from superacid. Nanotechnology 22, 075201 (2011)

37. Vosgueritchian, M., Lipomi, D.J., Bao, Z.: Highly conductive and transparent PEDOT:PSS films with a fluorosurfactant for stretchable and flexible transparent electrodes. Adv. Funct. Mater. 22, 421-428 (2012)

38. Hatton, R.A., Willis, M.R., Chesters, M.A., Briggs, D.: A robust ultrathin, transparent gold electrode tailored for hole injection into organic light-emitting diodes. J. Mater. Chem. 13, 722-726 (2003)

39. Hutter, O.S., Stec, H.M., Hatton, R.A.: An indium-free low work function window electrode for organic photovoltaics which improves with in-situ oxidation. Adv. Mater. 25, 284-288 (2013)

40. Lee, J., Lee, P., Lee, H., Lee, S.S., Ko, S.H.: Very long Ag nanowire synthesis and its application in a highly transparent, conductive and flexible metal electrode touch panel. Nanoscale 4, 6408-6414 (2012)

41. Joo, S.J., Park, S.H., Moon, C.J., Kim, H.S.: A highly reliable copper nanowire/nanoparticle ink pattern with high conductivity on flexible substrate prepared via a flash light-sintering technique. ACS Appl. Mater. Interfaces 7, 5674-5684 (2015)

42. Ye, S., Rathmell, A.R., Chen, Z., Stewart, I.E., Wiley, B.J.: Metal nanowire networks: the next generation of transparent conductors. Adv. Mater. 26, 6670-6687 (2014)

43. Finn, D.J., Lotya, M., Coleman, N.: Inkjet printing of silver nanowire networks. ACS Appl. Mater. Interfaces 7, 9254-9261 (2015)

44. Öhlund, T., Schuppert, A.K., Hummelgard, M., Bäckström, J., Nilsson, H.E., Olin, H.: Inkjet fabrication of copper patterns for flexible electronics: using paper with active precoatings. ACS Appl. Mater. Interfaces 7, 18273-18282 (2015)

45. Park, J.D., Lim, S., Kim, H.: Patterned silver nanowires using the gravure printing process for flexible applications. Thin Solid Films 586, 70-75 (2015)

46. Galagan, Y., Rubingh, J.E.J.M., Andriessen, R., Fan, C.C., Blom, P.W.M., Veenstra, S.C., Kroon, J.M.: ITO-free flexible organic solar cells with printed current collecting grids. Sol. Energy Mater. Sol. Cells 95, 1339-1343 (2011)

47. Araki, T., Sugahara, T., Jiu, J., Nagao, S., Nogi, M., Koga, H., Uchida, H., Shinozaki, K., Suganuma, K.: $\mathrm{Cu}$ salt ink formulation for printed electronics using photonic sintering. Langmuir 29, 11192-11197 (2013)

48. Müller-Meskamp, L., Schubert, S., Roch, T., Eckhardt, S., Lasagni, A.F., Leo, K.: Transparent conductive metal thin-film electrodes structured by direct laser interference patterning. Adv. Eng. Mater. 17(8), 1215-1219 (2015)

49. Higashitani, K., McNamee, C.E., Nakayama, M.: Formation of large-scale flexible transparent conductive films using evaporative migration characteristics of Au nanoparticles. Langmuir 27, 2080-2083 (2011)

50. Mohl, M., Dombovari, A., Vajtai, R., Ajayan, P.M., Kordas, K.: Self-assembled large scale metal alloy grid patterns as flexible transparent conductive layers. Sci. Rep. 5, 13710 (2015)

51. Ahn, T., Kim, H.J., Lee, J., Choi, D.G., Jung, J.Y., Choi, J.H., Jeon, S., Kim, J.D., Jeong, J.H.: A facile patterning of silver nanowires using a magnetic printing method. Nanotechnology 26, 345301 (2015)

52. Vakarelski, I.U., Chan, Y.C.C., Nonoguchi, T., Shinto, H., Higashitani, K.: Assembly of gold nanoparticles into microwire networks induced by drying liquid bridges. Rev. Lett. 102(058303), 1-4 (2009)

53. Gao, T., Wang, B., Ding, B., Lee, J.K., Leu, P.W.: Uniform and ordered copper nanomeshes by microsphere lithography for transparent electrodes. Nano Lett. 14, 2105-2110 (2014)

54. Hunger, C., Rao, K.D.M., Gupta, R., Singh, C.R., Kulkarni, G.U., Thelakkat, M.: Transparent metal network with low haze and high figure of merit applied to front and back electrodes in semitransparent ITO-free polymer solar cells. Energy Technology 3(4), 359-365 (2015)

55. Hong, S., Yeo, J., Kim, G., Kim, D., Lee, H., Kwon, J., Lee, H., Lee, Ph, Ko, S.H.: Nonvacuum, maskless fabrication of a flexible metal grid transparent conductor by low-temperature selective laser sintering of nanoparticle ink. ACS Nano 7(6), 5024-5031 (2013)

56. Zhou, W., Bai, S., Ma, Y., Ma, D., Hou, T., Shi, X., Hu, A.: Laser-direct writing of silver metal electrodes on transparent flexible substrates with high-bonding strength. ACS Appl. Mater. Interfaces 8, 24887-24892 (2016)

57. Buffat, Ph, Borel, J.P.: Size effect on the melting temperature of gold particles. Phys. Rev. A 13(6), 2287.-2298 (1976)

58. Goldstein, A.N., Echer, C.M., Alivisatos, A.P.: Melting in semiconductor nanocrystals. Science 256(5062), 1425-1427 (1992)

59. Hu, A., Guo, J.Y., Alarifi, H., Patane, G., Zhou, Y., Compagnini, G., Xu, C.X.: Low temperature sintering of Ag nanoparticles for flexible electronics packaging. Appl. Phys. Lett. 97, 153117 (2010) 
60. Dudina, D.V., Matvienko, A.A., Sidelnikov, A.A., Legan, M.A., Mali, V.I., Esikov, M.A., Gribov, P.A., Boldyrev, V.V.: Decomposition of $\mathrm{Ag}_{2} \mathrm{C}_{2} \mathrm{O}_{4}$ in a spark plasma sintering apparatus: morphological study and application for materials joining. Mater. Today. 16, 187-190 (2019)

61. Kang, B., Han, S., Kim, J., Ko, S., Yang, M.: One-step fabrication of copper electrode by laser-induced direct local reduction and agglomeration of copper oxide nanoparticle. J. Phys. Chem. C 115, 23664 23670 (2011)

62. Son, Y., Yeo, J., Moon, H., Lim, T.W., Hong, S., Nam, K.H., Yoo, S., Grigoropoulos, C.P., Yang, D.Y., Ko, S.H.: Nanoscale electronics: Digital fabrication by direct femtosecond laser processing of metal nanoparticles. Adv. Mater. 23, 3176-3181 (2011)

63. Yeo, J., Hong, S., Wanit, M., Kang, H.W., Lee, D., Grigoropoulos, C.P., Sung, H.J., Ko, S.H.: Rapid, one-step digital selective growth of $\mathrm{ZnO}$ nanowires on 3D structures using laser induced hydrothermal growth. Adv. Funct. Mater. 23, 3316-3323 (2013)

64. Haacke, G.: New figure of merit for transparent conductors. J. Appl. Phys. 47(9), 4086-4089 (1976)

65. Cao, W., Li, J., Chen, H., Xue, J.: Transparent electrodes for organic optoelectronic devices: a review. J. Photonics Energy 4, 040990-040991 (2014)

66. Lee, H.B., Jin, W.Y., Ovhal, M.M., Kumae, N., Kang, J.W.: Flexible transparent conducting electrodes based on metal meshes for organic optoelectronic device applications: a review. J. Mater. Chem. C 7, 1087-1110 (2019)

\section{Affiliations}

\section{Isabelle Pasquet ${ }^{1} \cdot$ Hoa Le Trong ${ }^{1}$ • Valérie Baco ${ }^{1}$ • Véronique Conédéra ${ }^{2}$. Henri Camon ${ }^{2} \cdot$ Philippe Tailhades $^{1}$}

1 Institut Carnot Chimie Balard Cirimat, UMR CNRS 5085, Université Toulouse III Paul Sabatier, 118 route de Narbonne, 31062 Toulouse Cedex 9, France

2 LAAS-CNRS, Université de Toulouse, CNRS, 7 avenue du Colonel Roche, 31400 Toulouse, France 